\title{
Opciones de defensa procesal en caso de firmeza de actos, reglamentos o sentencias
}

\author{
Santiago González-Varas Ibánez
}

Catedrático de la Universidad de Alicante

\begin{abstract}
RESUMEN: este trabajo explora posibles espacios de defensa en situaciones complicadas en que el particular no tiene en principio posibilidad alguna de recurso. Se trata, primero, de aportar un enfoque sistemático de las posibles situaciones, ya que se advierte especial confusión a la hora de enfocar estos temas. Segundo, identificar problemas en torno a este tipo de situaciones y aportar algunas posibles soluciones. Para ello, tercero, el método tendrá que ser, fundamentalmente, de aportación de criterios que operan en la práctica jurídica. Se discuten por ejemplo las opciones procesales del recurso contencioso-administrativo indirecto contra disposiciones generales a través de la impugnación de actos presuntos o expresos creados por peticiones en vía administrativa, las posibilidades de atacar un acto firme aprovechando la existencia de una sentencia posterior que lo contradice; se exploran márgenes de defensa que otorga la propia cosa juzgada (y sus relaciones también con el desistimiento y las sentencias de inadmisión), así como el recurso extraordinario de revisión de la LRJAPPAC 30/1992, la revisión de sentencias del artículo 102 de la LRJCA 29/1998 y la revisión de oficio de los actos administrativos nulos de gravamen.
\end{abstract}

PALABRAS CLAVES: indefensión, tutela judicial, defensa procesal, revisión de actos nulos, actos de gravamen, recurso extraordinario de revisión, desistimiento, inadmisión, cosa juzgada, prejudicialidad, disposiciones de carácter general.

\section{El equilibrio entre firmeza y tutela jurídica. Plantea- mientos adentrándose en lo incierto}

Litigar dentro de los plazos y trámites previstos se desarrolla dentro de una lógica diferente de cuando se ha producido la firmeza de actos o reglamentos o sentencias tras el plazo de recurso. Lo característico podrá ser buscar una salida (el "loophole" como dicen los letrados ingleses) para quienes precisan razonablemente tutela jurídica (Rechtschutzbedürfnis según el preciso -y adecuado al caso- vocablo alemán; art. $24 \mathrm{CE}$ ), ya que en estos casos el ordenamiento en principio puede haber cerrado las vías ordinarias de defensa. Este planteamiento es necesario pensando en los derechos de ciudadanos que pueden vivir situaciones dramáticas, aun reconociendo su excepcionalidad ante la existencia de límites en el ejercicio de los derechos, por razones lógicas de funcionamiento del servicio público de la justicia o por simples ra- 
zones de seguridad jurídica a favor de la Administración y de los propios ciudadanos beneficiados por los fallos o actos firmes.

\section{El problema con los actos. Opciones de defensa después de haber trascurrido el plazo de recurso contra el acto administrativo}
A. Vías ab initio cerradas; y otras en principio abiertas

En estos casos en que el acto ha devenido firme (por no haberse recurrido o haber trascurrido el plazo de recurso) será generalmente infructuoso el esfuerzo de intentar reabrir la causa creando un nuevo acto, ya que fácilmente el letrado de la Administración cerrará esta opción alegando la causa de inadmisión del artículo 28 de la LRJCA 29/1998. Todo ello conforme a una lógica, de aplicación casi diaria, diríamos, en la praxis del contencioso-administrativo. En cambio, si no existe un acto previo de referencia, firme y consentido, siempre estará abierta esta vía, a veces un tanto informal e indefinida en sus resultados finales, de la creación de un acto mediante la presentación de una petición que, en todo caso, puede reiterarse mientras la Administración haya mantenido silencio (considerando además la consolidada jurisprudencia que ha superado el criterio legal del artículo 46.1 LJCA de los seis meses de plazo para acudir a la jurisdicción contencioso-administrativa una vez que se ha creado un acto presunto mediante una petición en vía administrativa ${ }^{1}$ ).

Tampoco se abren claras opciones en torno a la lesividad (en el sentido de que el particular no cuenta con una acción para obligar judicialmente a la Administración a que la inste) o a la revocación del artículo 105 LRJAP-PAC (ya que "si se reconociera a los ciudadanos legitimación para instar la incoación del procedimiento de revocación, se quebraría el sistema de recursos administrativos", STSJ de la Comunidad Valenciana de 23 de marzo de 1999; pese a que esta misma sentencia fija algunos límites a la potestad revocatoria en el contexto del principio de igualdad).

Más bien, tales opciones pasan por los márgenes que otorga la revisión de oficio o el recurso extraordinario de revisión, ambos regulados en la LRJAP-PAC 30/1992, siendo el legislador consciente de la necesidad de abrir alguna vía de defensa en casos en que se han cerrado en principio tales márgenes, ante la imposibilidad de recurrir por trascurso del fatal plazo. Se abren tales opciones pero de forma limitada y un tanto excepcional como vamos a ver.

\footnotetext{
${ }^{1}$ Las sentencias hoy día son numerosas (algunas son: STS de 12 junio 2001 y STC 14/2006)
} 


\section{B. Revisión de oficio en este contexto}

Pues bien, centrándonos en esta primera vía de solución contra la firmeza del acto, en este mundo jurídico de equilibrios, la Ley 30/1992 (artículo 102) permite la posibilidad de la revisión de oficio, que en principio otorga un gran poder al interesado, ya que la acción de nulidad para obligar a la Administración a revisar un acto procede en cualquier momento, estando dicha Administración obligada a revisar el acto, con lo que, si ésta se resiste, aquel acudirá a los juzgados o tribunales y conseguirá obligar a que revise el acto.

La acción de nulidad, en el contexto de la revisión de oficio, opera desde luego como un posible remedio para evitar la dura firmeza, en relación con actos dictados en favor de otros particulares que se beneficiaron de los mismos y que pudieron quedar tranquilos ante lo asentado de la situación jurídica creada por un acto no recurrido en tiempo y forma, especialmente una vez que han podido pasar hasta lustros desde que la licencia fue otorgada o desde que se produjo el nombramiento como funcionario o desde la adjudicación del contrato administrativo. Hasta que, precisamente, en cualquier momento, irrumpe la acción de nulidad de otro sujeto obligando a la Administración a que revise de oficio el acto. El susto puede ser mayúsculo cuando, por poner un ejemplo, el particular compra una casa con licencia en suelo no urbanizable incluso tras sucesivas compraventas, dando por hecho que con tener la licencia está en regla. El asunto podrá remitir a una nueva causa, indemnizatoria, que, pese a lo que se piensa por algunos, no siempre es del todo favorable al particular afectado, ya que habrá que examinar las causas del otorgamiento de la licencia en cuestión y quien produjo el posible vicio (¿por culpa de la Administración, realmente, o debido al error causado por los documentos el promotor? ¿Será éste solvente? ¿Se perderá, incluso, el contencioso-administrativo, por no poderse imputar el daño a la Administración? En un plano más teórico, la cuestión parece, además, llevar a situaciones incluso contradictorias, porque, según parece, puede darse la paradójica situación de que el particular que construye sin licencia (o adquiere una construcción en tal situación) podría estar mejor a cubierto frente a la acción de nulidad que aquel que cuenta con la misma, pese a ser nula, ya que en este segundo caso el ciudadano está más expuesto a la acción de nulidad imprescriptible.

Se entiende, así, que, ab initio, ha de frenarse el posible ímpetu del interesado en ejercitar la acción de nulidad, haciendo pasar esta acción por el alambicado filtro de la "nulidad" de pleno derecho (STS de 22 de marzo de 2005; artículo 62 de la misma ley, lo que a veces lleva a hacer un encaje de bolillos, en especial en torno a las letras "c" y "f"). Y, sin obviar, ese otro límite, a la imprescriptibilidad de la acción (de creciente consideración por los tribunales), previsto en el artículo 106 de la LRJAPPAC ("las facultades de revisión no podrán ser ejercitadas cuando por prescripción de acciones, por el tiempo transcurrido o por otras circunstancias, su ejercicio resul- 
te contrario a la equidad, a la buena fe, al derecho de los particulares o a las leyes"). $\mathrm{O}$ sin olvidar tampoco las diversas incidencias que se puedan producir en torno al procedimiento de revisión, con la propia facultad de la Administración de inadmitir la acción de nulidad si no cuenta con cierto fundamento prima facie (tema sobre el cual, igualmente, se producen numerosas incidencias en la práctica jurídica) o de los propios tribunales de confirmar que las opciones de defensa pasaron por las vías de recurso cuyo plazo se dejó trascurrir (STSJ de Madrid de 3 de noviembre de 2010, JUR 2011 \42527; STS de 12 de julio de 2012 RJ 8483).

$\mathrm{Y}$, pese a todo, tiene razón la doctrina cuando apunta que la revisión de oficio es, en cuanto tal, una garantía para el afectado, ya que evita que, además de lo expuesto, eso mismo lo hiciera la Administración dictando simplemente un nuevo acto en sustitución del dictado, al margen del mecanismo y procedimiento y garantías de la revisión de oficio (STS de 10 noviembre 2006).

Pasamos por alto temas de tratamiento sencillo, para observar en el contexto de la revisión de oficio, la situación siguiente, sin perjuicio de otras que igualmente nos ocuparán más adelante.

\section{B. Acción de nulidad contra acto firme de gravamen}

En efecto, más compleja es la situación que se refiere directamente al interesado que no tiene ya plazo para recurrir un acto de gravamen que le afecta directamente. Por otro lado, considérese que la fuerza mayor, prevista en la LEC para reabrir un plazo ya cerrado, no es una vía que permita en la práctica procesal especiales opciones de defensa.

Cierto que, aunque el artículo 102 de la LRJAP-PAC no distingue más allá de la causa de nulidad, lo normal es que la potestad de revisión de oficio y desde luego la de lesividad se refiera a actos favorables, cuya anulación interese a un tercero o a la Administración misma; y la de revocación a los actos de gravamen ${ }^{2}$, no faltando incluso algunos pronunciamientos judiciales que dan por hecho que la revisión de oficio solo puede aplicarse a las revisiones o acciones de nulidad contra actos favorables, por tanto en favor de terceros (SSTSJ de la Comunidad Valenciana de 23 de marzo de 1999; y de de 12 de febrero de 2000).

${ }^{2}$ STSJ de Castilla-La Mancha 649/2003 de 7 noviembre; STS 29 de septiembre de 2003; STS 29 de septiembre de 2003. 
Sin embargo, está admitida la acción de nulidad para instar la revisión de oficio contra actos nulos de gravamen. Se observan casos en los que el propio interesado que es destinatario de un acto administrativo de gravamen insta la acción de nulidad del artículo 102 de la LRJAP-PAC, a fin de solicitar que se revise de oficio dicho acto por incurrir en alguna causa de nulidad de pleno Derecho. No vamos tampoco a extendernos más, en torno a las posibles incidencias que plantea su ejercicio ${ }^{3}$, a fin de reservar espacio para ir presentando sistemáticamente más situaciones posibles en torno a este debate procesal relacionado con firmezas y cosas juzgadas.

\section{Recurso extraordinario de revisión}

Diríamos que la vía de la revisión de oficio y del recurso extraordinario de revisión vienen a ser dos cauces que se enfrentan con el problema jurídico-administrativo de la firmeza del acto una vez transcurre el plazo de impugnación. Dicho recurso viene configurándose como un recurso extraordinario, procediendo contra un acto firme, a diferencia de los de alzada y de reposición, estando los motivos para su interposición tasados. Y por ello mismo no procederá cuando la cuestión pueda ventilarse mediante recursos ordinarios (STS de 20 de diciembre de 2006). En el Derecho alemán se dice que, en estos casos, no existe "necesidad de protección jurídica" para el medio extraordinario cuando vale otra acción ordinaria.

Lo primero a la hora de plantear este recurso es que el supuesto encaje en los supuestos legales (Dictamen del Consejo de Estado 605/2008). Además, conforme a su carácter extraordinario, los motivos de recurso han de ser de interpretación restrictiva (STS de 4 de marzo de 2008). De ahí que en relación con el primer motivo previsto legalmente los errores han de ser fácticos, no jurídicos o de apreciación (STS de 25 de junio de 1974).

3 STS de 20 de mayo de 2009 recurso 204/108/2007; STS 27 de Febrero 2004 recurso 201/118/03; STSJ de Canarias, sede de Tenerife, núm. 1414/1998 de 23 diciembre; STSJ de la Comunidad Valenciana de 23 de marzo de 1999 «los actos nulos de pleno derecho, ya fueren declarativos de derecho, ya de gravamen, también podrán ser revisados, a tenor de lo que previene el artículo 102»; STSJ de Extremadura de 20 de febrero de 2007). En especial dejamos constancia de los Dictámenes (protagonistas en esta materia) del Consejo de Estado núm. 263 de 18 marzo 1998, $\mathrm{n}^{\mathrm{o}} 4134$ de 10 de diciembre de 1998, 4909/98 de 11 febrero de 1999, 21/1999 de 18 febrero de 1999; 69/2000 de 23 marzo de 2000; 1949/2000 de 22 junio 2000, 4441/98 de 28 enero de 1999 y 6049/97 de 26 febrero de 1998; Dictamen del Consejo Jurídico de la Región de Murcia 241/10). 
Dejamos planteada la cuestión sobre la que volveremos después, sobre este recurso, en el contexto de una problemática especial, relativa a la procedencia de este recurso extraordinario contra un acto firme aprovechando una sentencia posterior que pone de manifiesto el error del acto.

\section{El problema con los reglamentos. Opciones de defensa después de haber trascurrido el plazo de recurso contra la disposición de carácter general}

Situaciones complejas de defensa pueden plantearse cuando el reglamento es firme por haber trascurrido el plazo de impugnación. En estos casos, no procede la acción de nulidad. El legislador ha trazado la línea fronteriza, entre seguridad jurídica y apertura de márgenes de defensa, en ese punto dejando al margen la acción de nulidad para la revisión de la disposición nula. El artículo 102.2 de la LRJAP-PAC fue introducido por la Ley 4/1999, de modo que la revisión de oficio de los Reglamentos, que había desaparecido de la Ley procedimental con la Ley 30/1992, fue restituida por la Ley 4/1999, rezando actualmente: "en cualquier momento, las Administraciones públicas de oficio, y previo dictamen favorable del Consejo de Estado u órgano consultivo equivalente de la Comunidad Autónoma si lo hubiere, podrán declarar la nulidad de las disposiciones administrativas en los supuestos previstos en el artículo 62.2" (STS de 5 de noviembre de 2010; STS de 22 de diciembre de 1999; STS de 28 de noviembre de 2001; STS de 19 de marzo de 2008; STS de 22 de noviembre de 2006 recurso 4084/03; STSJ del País Vasco de 8 de febrero de 2007; STS de 28 de noviembre de 2001).

Quien pretenda la anulación de una norma tiene que impugnarla en el plazo debido de los dos meses después de su publicación; o bien también se puede pretender la anulación de una norma reglamentaria por la vía del recurso contencioso-administrativo indirecto, es decir, recurriendo un acto de aplicación de la norma para conseguir la anulación de la norma misma (tal como corrobora la STS de 13 de julio de 2000 RJ 9054). Por cierto, con este planteamiento jurídico se entiende que cobre especial interés a veces dilucidar si estamos ante un acto o ante una norma (SAN de 3 de mayo de 2007, JUR 13668), al proceder la acción de nulidad por revisión de oficio en el primer caso pero no en el segundo ${ }^{4}$.

${ }^{4}$ Por ejemplo, los Estudios de Detalle son normas, no actos, de modo que su recurribilidad pasa ora por su impugnación indirecta, ora por su revisión de oficio por la Administración que los dictó (STS de 5 de octubre de 2001, RJ 7960; STSJ de Canarias, sede de Las Palmas, de 10 de marzo de 2008, JUR 164813; STS de 17 abril de 2013 RJ 2013\3569; STS de 11 de abril de 2013 RJ $3351)$. 
Por lo tanto, el caso normal de ejercicio del recurso contencioso-administrativo indirecto se refiere a la defensa procesal contra un acto dictado por la Administración, interesando al afectado ejercitar una pretensión anulatoria contra el acto invocando que éste es ilegal porque lo es el propio reglamento de aplicación ${ }^{5}$.

Ahora bien, el recurso contencioso-administrativo indirecto no debe limitarse al caso en que existe un previo acto expreso dictado por la Administración en aplicación del Reglamento, ya que, a mi juicio, también ha de permitirse tal recurso indirecto tras la creación por el interesado (previa petición en vía administrativa) de un acto, expreso o presunto, a fin de impugnarlo después mediante este cauce del recurso contencioso administrativo indirecto; no se puede condicionar la defensa procesal a que la Administración haya dictado motu proprio un acto de aplicación del reglamento o a que se impugne la disposición en el plazo de dos meses. De cerrar "también" (junto a la acción de nulidad posterior al reglamento) esta vía del recurso indirecto contra el acto creado vía petición, se pueden producir casos de indefensión, en supuestos en que los incumplimientos mismos, en la aplicación del reglamento en cuestión, se originan incluso hasta años después de que la disposición se haya dictado, situaciones que a veces se relacionan con gravámenes insostenibles que no se manifestaban en el momento de dictarse un determinada norma o plan, pero que se producen en un momento posterior, sin que tampoco siempre en estos casos se identifique un acto en aplicación del Reglamento que poder servir de excusa para defenderse.

Por poner un ejemplo, si un Plan General, vía modificación, clasifica toda una zona como suelo urbanizable, dejando sin embargo un islote como no urbanizable, no entenderíamos por qué no se puede intentar recurrir por el particular el Plan General creando un acto de aplicación (reclamando la condición de urbanizable e invo-

${ }^{5}$ Un ámbito donde se debaten este tipo de acciones, con resultados diferentes, es el de la pretensión de declaración de ilegalidad del planeamiento a través del recurso contra el acto reparcelatorio. Ahora bien, si no se plantean propiamente temas «normativos» (o «de ordenación»), susceptibles de impugnación indirecta, no cabrá admitir, lógicamente, el recurso a través del acto de reparcelación. La cuestión pasa por empezar observando si la pretensión ejercitada se refiere en realidad a temas de programación o de gestión o de selección del urbanizador, es decir, ajenos al planteamiento. La impugnación indirecta a través de la reparcelación presupone cuando menos que el recurrente plantee temas de ordenación, tal como explica la STS de 24 de marzo de 2004, recurso $6461 / 2001$. Si se evidencia que el interesado fuerza el recurso, este será inadmisible: al no haberse utilizado la vía de la impugnación directa no puede después repetirse utilizando la vía de la impugnación indirecta (Sentencia n ${ }^{\circ}$ 298/2006 de fecha 13 de marzo de 2006, del Tribunal Superior de Justicia de la Comunidad Valenciana). Con mayor motivo no cabrá la impugnación indirecta del propio acto de reparcelación o del proyecto de urbanización, como afirma la sentencia del TSJ de la Comunidad Valenciana, de fecha 3 septiembre 2008, nº 1303/2008, rec. 1106/2007, FJ $4^{\circ}$. 
cando arbitrariedad) para aplicar después la lógica del contencioso indirecto contra el plan en cuestión. No obstante, en la práctica judicial a veces se observa poca atención sobre toda esta cuestión que estamos comentando. Habría en mi opinión que interpretar toda esta situación a la luz de la tutela judicial efectiva, la ausencia de indefensión y el pro actione, para reservar la inadmisión para los casos en que existan claros motivos fundados de que el particular omitió el recurso en el plazo de dos meses de impugnación desde la publicación de la disposición (en este contexto, inadmitiendo, ATSJ n ${ }^{\circ} 709$ de la Comunidad Valenciana de 8 de noviembre de 2010, PO 299/2009). Un ejemplo de la procedencia del recurso contencioso-administrativo indirecto, contra un acto (si bien expreso) producido por la vía de una petición formulada en vía administrativa por el particular es la sentencia del TSJ de La Rioja de 8 de julio de 2008 (sentencia 159/2008) siguiendo la lógica de la solicitud de acto, denegación de la solicitud y presentación acto seguido del recurso indirecto contra Reglamento (véanse también las STS de 17 de octubre de 2002, STSJ de Madrid de 25 de junio de 2002, STSJ de Cantabria de 14 de septiembre de 2001, etc.). Es decir, en el caso de la sentencia del TSJ de La Rioja de 8 de julio de 2008, 159/2008 el recurrente había presentado una solicitud en vía administrativa a fin de que se reconociera su derecho a ejercer la objeción de conciencia, recurriendo posteriormente el acto originado por dicha solicitud en vía administrativa, siendo la pretensión de fondo del actor que el acto recurrido era ilegal por que los reglamentos de referencia de dicho acto eran asimismo ilegales, que es la lógica del recurso contencioso-administrativo indirecto ${ }^{6}$.

\footnotetext{
${ }^{6}$ Reproduzco algunas líneas de esta sentencia: «Tampoco ha de estimarse la alegación en que el Abogado del Estado señala que los recurrentes no han formulado una impugnación indirecta de los reglamentos ni procedería la directa. Y no es de estimarla porque el planteamiento de la acción en el presente recurso es el siguiente: se impugna por los actores un acto administrativo singular de la Administración educativa autonómica que denegó la solicitud de objeción de conciencia formulada al amparo de los expresados derechos fundamentales. Se solicita en la demanda la nulidad de dicho acto administrativo y se formulan pretensiones de reconocimiento de una situación jurídica individualizada y la adopción de las medidas adecuadas para el pleno restablecimiento de la misma, consistente, en esencia, en la exención de referida obligación, y que por consiguiente se declare por los tribunales a su hijo exento de cursar las nuevas asignaturas litigiosas sin consecuencias negativas a la hora de promocionar de curso u obtener los títulos académicos correspondientes. Pero es que también se impugna por los actores, indirectamente, el contenido de los Reales Decretos que regulan precisamente esas nuevas asignaturas de educación para la ciudadanía, tal y como claramente se desprende del escrito de demanda, la cual se fundamenta en que tales disposiciones generales no son conformes a derecho, siendo esto (la dicha fundamentación) precisamente lo que prevé el artículo 26 de la Ley reguladora de la jurisdicción Contencioso-Administrativa cuando regula la denominada impugnación indirecta de reglamentos (...)"
} 
En definitiva, la improcedencia de ejercitar la acción de nulidad del artículo 102 de la LRJAP-PAC 30/1992 en el caso de los reglamentos, y la imposibilidad hasta de facto muchas veces de recurrir una disposición en el plazo de dos meses desde su publicación, lleva a la necesidad de no cerrar la vía a la impugnación indirecta de una norma reglamentaria mediante el recurso contencioso indirecto contra el acto presunto o expreso por el que se resuelva una petición del particular, como cauce de defensa para poder llevar al tribunal un reglamento más allá de tal plazo de dos meses o cuando no exista un acto dictado por la Administración en su aplicación, pero sí una necesidad de tutela judicial efectiva. En esta línea, es interesante la STS de 29 de febrero de 2012 (RJ 4747) cuando descarta interpretaciones rigoristas, como la que había sostenido la Sala de instancia (revocando su sentencia), admitiendo el recurso indirecto contra el acto creado por petición del particular instando la modificación de un Plan General (si bien con motivo de una reforma normativa posterior a tal PGOU) que amparaba tal petición. Igualmente, es interesante la STS de 3 de septiembre de 2003 (recurso 165/2000) en la que el Tribunal Supremo desoye el argumento de la sentencia de instancia de que el recurrente está "aprovechando la generación de nuevos actos administrativos" para forzar el recurso contencioso-administrativo indirecto (se trataba de la impugnación de una modificación de un Plan General a través de un acto reparcelatorio). El TS da por hecho la procedencia de tal recurso contencioso-administrativo planteado de esta forma y estima el recurso de casación, por lo que anula la modificación puntual del Plan General en cuanto no incluyó en un determinado sector (zona industrial) los terrenos propiedad de la entidad recurrente.

El contencioso-administrativo español funciona de una forma simple, mediante esta lógica de ir creando actos, pese a que no quedan claros, como podemos apreciar, los criterios para ello, ni los límites ni los posibles resultados.

\section{El problema con las sentencias. En torno a la cosa juzga- da o la prejudicialidad resuelta}

A. El punto de partida en la seguridad jurídica necesaria, que a todos nos favorece.

El efecto de cosa juzgada constituye una garantía esencial de la seguridad jurídica que se configura como la vinculación que produce el fallo de una sentencia firme en otro proceso ulterior, como consecuencia de un mandato imperativo de naturaleza jurídico-pública dirigido al Juzgador con la finalidad de evitar resoluciones judiciales contradictorias o, incluso, nuevas decisiones sobre lo ya juzgado. De dicha «vinculación» se derivan dos efectos de alcance y tratamiento procesal diferentes, uno de carácter negativo, en virtud del cual queda excluido un nuevo pronunciamiento de fondo sobre el mismo asunto, en el sentido clásico de la «exceptio rei iudica- 
tas y otro de signo positivo, según el cual el segundo pronunciamiento debe respetar lo que fue decidido en el primero cuando esta decisión actúe como elemento prejudicial (STS de 16 de enero de 1998). Este último efecto constituye lo que podemos también denominar «cuestión de prejudicialidad resuelta».

Explicar, en cuanto tal, la cosa juzgada no tiene mayor interés, ya que donde estará el quid será más bien en los recovecos del asunto, en un planteamiento procesal garantista, explorando las posibles opciones, cuando puedan existir razones fundadas para defenderse frente a la adversidad y los límites lógicos generales que impone el legislador y la propia jurisprudencia.

El tema de la cosa juzgada se relaciona directamente con la discusión de si existen o no las tres identidades procesales que constituyen el elemento de contraste necesario para determinar sus propios presupuestos: identidad de sujetos, objeto y causa de pedir. Con esto se alude a que la sentencia que se invoca ha de «afectar a los mismos sujetos contendientes, ha de versar sobre el mismo objeto, y en fin, ha de pronunciarse únicamente por la causa que se alegó para deducir las pretensiones, por lo que sólo cuando el proceso futuro es idéntico en razón de estos tres elementos el proceso fallado produce la cosa juzgada» (STS de 26 de julio de 1996; STS de 5 de octubre de 1995; STS de 12 de diciembre de 2012 RJ 2013\1032 FJ 5 ${ }^{\circ}$, con otras citas de sentencias; artículos 1251 y 1252 del CC) $)^{7}$.

\section{B. Vinculación de la jurisdicción contencioso-administrativa al cri- terio sentado por otra jurisdicción}

Antes de entrar en situaciones más complejas, es oportuno profundizar en el planteamiento hecho, estudiando los efectos que tienen pronunciamientos ya existentes de otra jurisdicción- a la hora de dictar sentencia por parte de un órgano de la jurisdicción contencioso-administrativa. Esto es interesante para observar, primeramente, cómo determinados particulares que obtienen un pronunciamiento favorable en

\footnotetext{
${ }^{7}$ Para la STSJ de Cantabria de 3 de diciembre de 2012 (recurso 95/2012) es preciso evitar (con apoyo en el artículo 222.4 de la LEC) que la "controversia se renueve o que se actúen pretensiones que contradigan el sentido de la sentencia firme, siempre partiendo de la certeza de una resolución sobre idéntico conflicto, aun recaído en procedimiento de distinta naturaleza", si bien en el asunto enjuiciado finalmente lo que se identifica es que el recurrente está provocando la creación simplemente de un nuevo acto para reabrir una causa juzgada. Por tanto, no puede estimarse cosa juzgada si «las peticiones son distintas por estar basadas en causas de pedir también diferentes: derecho a devolución de fianza y posterior discusión sobre indemnización por devolución tardía de la fianza» (STS de 22 de abril de 1996).
} 
una determinada jurisdicción pueden así beneficiarse -en otro proceso- del criterio ya sentado por la primera de las sentencias dictadas. Para ello invocan los tribunales la cosa juzgada, con lo que ésta ya no puede verse (al menos siempre) como la típica causa de inadmisión que cierra opciones de defensa procesal sino, como vemos, como un motivo que refuerza determinadas pretensiones adquiridas judicialmente, de cara a otros posibles procesos.

Por otro lado, este tema nos permitirá asimismo introducir un peculiar debate acerca de las opciones procesales de defensa cuando existe un acto administrativo firme y, con posterioridad, se dicta una sentencia que contradice lo resuelto por el acto administrativo, abriendo por tanto opciones frente a la fatal firmeza. Pondremos ejemplos más adelante, ya que conviene ir por partes, a la hora de explicar esta cuestión, observando primero ciertas sentencias de interés.

Antes, afirmar que la vinculación de la jurisdicción contencioso-administrativa por el criterio sentado por sentencia de otra jurisdicción se suele enfocar desde la cosa juzgada, pese a que parecería mejor la prejudicialidad resuelta, bien homogénea o heterogénea, dependiendo, respectivamente, de si el criterio resolutorio firme procede de la misma o de otra jurisdicción, como permite afirmar la doctrina general de Derecho procesal. Este planteamiento lleva (aun sin querer entrar aquí en pormenores procesales) ora a distinguir el caso en que existe una sentencia anterior de referencia a otra posterior, ora el caso del proceso anterior que se está tramitando antes de otro posterior con el cual guarda estrecha relación, imponiéndose la suspensión del proceso más reciente (no hay litispendencia en estos casos, sino prejudicialidad; además, ésta conlleva "suspensión" y, en cambio, aquella "inadmisión", al igual que la cosa juzgada).

En cuanto a la doctrina aplicable, puede citarse primeramente la STS de 18 de julio de 2012 (RJ 2012\8660), -en relación con otra sentencia recaída en un proceso contra el mismo acto administrativo que el que resulta ser objeto del recurso de casación (una Orden aprobando un deslinde de los bienes de dominio público marítimo-terrestre), aunque interpuesto por un recurrente diferente-, indica que tiene un efecto idéntico al de la cosa juzgada el supuesto de un conflicto al que la jurisdicción ha dado una respuesta, que no cabe desconocer posteriormente: "a pesar de no estar ante cosa juzgada, por no concurrir las identidades precisas para ello, tampoco se puede desconocer que esta misma Sala del Tribunal Supremo ha declarado, entre otras, en sus Sentencias de fechas 10 de junio de 2000 (RJ 2000, 7154) (recurso de casación 919/1996, fundamento jurídico quinto), 29 de junio de 2002 (RJ 2002, 7981) (recurso de casación 1635/1998, fundamento jurídico segundo), 2 de diciembre de 2003 (recursos de casación 7365/1999 (RJ 2004, 307), fundamento jurídico segundo y 8074/1999 (RJ 2004, 308), fundamento jurídico segundo), y 17 de mayo de 2006 (RJ 2006, 6967) (recurso de casación 1530/2003, fundamento jurídico tercero), que los principios de igualdad jurídica y de legalidad en materia procesal im- 
piden desconocer o reabrir el análisis de lo ya resuello por sentencia firme, efecto que no sólo se produciría con el desconocimiento por un órgano judicial de lo resuelto por otro en supuestos en que concurran las identidades de la cosa juzgada, sino también cuando se elude lo resuelto por sentencia firme en el marco de procesos que examinan cuestiones que guardan una estrecha dependencia, aunque no sea posible apreciar el efecto de la cosa juzgada (Sentencias del Tribunal Constitucional 182/1994 (RTC 1994，182), 171/1991 (RTC 1991，171), 207/1989 (RTG 1989, 207) ó 58/1988 (RTC 1988, 58)). No se trata, decíamos en aquellas sentencias, de una cuestión que afecte a la libertad interpretativa de los órganos jurisdiccionales, sino de salvaguardar la eficacia de una resolución judicial que, habiendo ganado firmeza, ha conformado la realidad jurídica de una forma cualificada que no puede desconocerse por otros órganos juzgadores ni reducir a la nada la propia eficacia de aquélla. La intangibilidad de lo decidido en una resolución judicial firme, fuera de los casos legalmente establecidos, es, pues, un efecto íntimamente conectado con la efectividad de la tutela judicial, tal como se consagra en el artículo 24.1 de la Constitución, de suerte que éste es también desconocido cuando aquélla lo es, siempre y cuando el órgano jurisdiccional conociese la existencia de la resolución judicial firme que tan profundamente afecta a lo que haya de ser resuelto. No estamos, por tanto, ante una controversia basada en autoridad de cosa juzgada sino frente a un conflicto al que la jurisdicción ha dado una respuesta, que no cabe desconocer ahora, de modo que todas las razones y argumentos, ya expresados para solucionarlo, han de ser reproducidos en cuanto guarden relación con los esgrimidos en este recurso de casación.".

Entrando ya en ejemplos sencillos, la STS de 21 de enero de 1986 (RJ 1568) afirma que al haberse resuelto por la jurisdicción civil la cuestión de la titularidad dominical del bien, la jurisdicción contencioso-administrativa queda vinculada por este pronunciamiento previo y no conoce del asunto.

La STSJ de Extremadura de 26 de marzo de 2014 (recurso 219/2012) estima el recurso declarando improcedente una sanción, considerando que la propiedad del bien no era del recurrente, ya que había una previa sentencia de la jurisdicción civil declarando que aquella era de su esposa tras una separación matrimonial (en sentido similar, pero con suerte contraria, STSJ de Castilla y León, Valladolid, de 3 de marzo de 2014 recurso $\left.1867 / 2010^{8}\right)$.

\footnotetext{
${ }^{8}$ Es ilustrativa la STS de 19 de octubre de 2010 (recurso 136/2006) cuando por un lado se considera vinculada por los hechos probados en una sentencia laboral firme anterior pero sintiéndose libre en la "valoración jurídica de tales hechos" considerando el ámbito jurídico interpretativo distinto de los mismos: "la circunstancia relevante de que los hechos analizados por dicha sentencia firme de la jurisdicción laboral (...) sean los mismos que los que aquí deben ser analizados (solo añadiendo nosotros los de fecha posterior) nos obliga a partir del relato de hechos probados contenido en dicha sentencia firme de la jurisdicción laboral, relato de hechos que aquí debemos respetar por
} 
La sentencia 1315/2005 del TSJ de Cataluña de 19 de diciembre de 2005 (n ${ }^{\circ}$ de recurso 45/2002) afirma que "para resolver la controversia habremos de traer a colación los razonamientos que contiene la sentencia dictada por la Sala de lo Social de este Tribunal Superior, en cuanto constituyen un antecedente y tienen efectos prejudiciales en este proceso". Se trataba de una sentencia de lo social donde se declaraba que el contrato del recurrente (personal laboral de la Administración) era indefinido, declarando improcedente el despido y condenando a la Administración a la readmisión del empleado. Este criterio de la Sala de lo social sirvió a esta sentencia 1315/2005 para fallar que tenía la actora que ser admitida en el concurso oposición restringido para la provisión de 14 plazas de técnico superior de gestión. Estimando por tanto el recurso extraordinario de revisión (del art. 118 de la LRJAP-PAC).

Ahora bien, una cosa es considerar, en un proceso contencioso-administrativo por ejemplo, el criterio de una sentencia preexistente de otro órgano jurisdiccional (dictando un fallo coherente con aquella), o incluso suspender un proceso considerando la existencia de un proceso anterior relacionado (por pura prejudicialidad); y otro debate, más complejo, es el de si un acto firme o una sentencia firme de la jurisdicción contencioso-administrativa pueden cuestionarse (revisarse, diríamos) por el hecho de que ha habido otro fallo posterior que ha puesto en evidencia errores fácticos del acto o de la sentencia en cuestión. Es evidente que, en principio, no hay solución fácil en estos casos, pese a que es conveniente explorar la situación.

Una primera referencia es la STJUE de 13 de enero de 2004 (y otras citadas, igualmente, en el voto particular de la STSJ de la Comunidad Valenciana de 13 de noviembre de 2012; JUR 2013\21811) al declarar la necesidad de revisar las decisiones admi-

elementales exigencias jurídicas del principio de seguridad jurídica, así como del derecho a la tutela judicial efectiva (...). En cambio, entendemos que no existe vinculación alguna de esta Sala en relación con la valoración jurídica que de esos mismos hechos se haya realizado en dicha sentencia laboral, pues tal valoración lo era desde la perspectiva del artículo 5.3 del RD 63/1995 y en este caso debe serlo desde una perspectiva jurídica diferente, cual es la de la concreta acción de responsabilidad patrimonial de la Administración que aquí se ejercita".

También se observa vinculación de la jurisdicción contencioso-administrativa a un fallo previo de la jurisdicción civil (donde se determinada si el bien era público o privado, concluyéndose esto último) en la STS de 4 de abril de 2014 (recurso 688/2012) citando otra precedente de 2007 del mismo TS con igual criterio, confirmando el TS además la posibilidad de suspender el proceso si se está ventilando tal cuestión en vía civil, ya que, pese a que la jurisdicción contencioso-administrativa puede conocer de cuestiones prejudiciales civiles, procede tal suspensión a la espera del fallo civil cuando la prejudicial no es accesoria sino principal.

En este mismo sentido, la STS de 17 de julio de 1990 RJ 6640 se considera vinculada por un previo pronunciamiento de la jurisdicción civil (declarando que no hubo sobreprecio) de modo que "desde luego" procede dejar sin efecto el acto administrativo. Puede verse asimismo la STSJ de Madrid de 23 de enero de 2007, RJCA 2007\533). 
nistrativas firmes que resulten contrarias a la jurisprudencia sobrevenida de este Tribunal, con lo cual el Derecho comunitario ampara las pretensiones de los funcionarios a cobrar trienios "con efectos retroactivos desde la fecha de expiración del plazo impartido a los Estados miembros para la trasposición de la directiva al Derecho interno".

No vamos a agotar todas las posibles dimensiones de este tema, que nos llevaría a presentar distintas situaciones en torno a la prejudicialidad, o a estudiar la cuestión de las sentencias que anulan disposiciones de carácter general y sus efectos sobre actos firmes o actos recurridos o sobre procesos abiertos. $\mathrm{O}$ en general la vinculación de una sentencia sobre casos similares en el marco de la jurisprudencia. No obstante, vamos a avanzar en estas situaciones comentadas observando algunas posibilidades que se abren, de discutir el acto firme, no tanto (como veremos) la sentencia firme, cuando se produce una sentencia posterior que pone en evidencia el error fáctico en que se basó dicho acto firme. En un Estado de Derecho interesa la seguridad jurídica, pero también que se depuren los vicios jurídicos de pura legalidad.

C. Debate sobre el recurso extraordinario de revisión (artículos 118 y 119 de la LRJAP-PAC) cuando se produce una sentencia posterior al acto firme que interesa contradecir

Junto al supuesto del artículo 118.1.1 de la LRJAP-PAC (que permite este recurso extraordinario de revisión cuando al dictar el acto firme se hubiera incurrido en error de hecho, que resulte de los propios documentos incorporados al expediente ${ }^{9}$ ) el artículo 118.1.2 de la LRJAP-PAC permite este recurso en casos en que "aparezcan documentos de valor esencial para la resolución del asunto que, aunque sean posteriores, evidencien el error de la resolución recurrida".

Por tanto, documentos, aunque posteriores, que no estaban al alcance del interesado en el momento en que fue dictada la resolución cuya revisión se pretende (STS de 21 de octubre de 2009, RJ 1118). Siendo "esencial" el documento cuando el resultado habría variado sustancialmente a la hora de decidir (Dictámenes del Consejo de Estado 1662/1996, de 23 de mayo; 950/2011 de 28 de julio de 2011 a favor del recurrente $)^{10}$. Presupuestos éstos que explican que puedan contraponerse al hecho de la firmeza.

${ }^{9}$ Dictámenes del Consejo de Estado 986/2002 de 30 de mayo de 2002 y 978/2000 de 8 de junio de 2000; Dictamen del Consejo de Estado 974/2009 de 9 de julio de 2009, evidenciando también un error de hecho que se aprecia de forma ostensible y clara.

${ }^{10}$ En el Dictamen 366/2012 de 20 de junio de 2012 se enfrenta el Consejo de Estado con un recurso de revisión contra un acto del Tribunal Administrativo de Contratación Pública de la Comunidad de Madrid concluyendo la procedencia del recurso extraordinario de revisión, ya que di- 
El Consejo de Estado resalta (citando la STS de 14 de noviembre de 2011) que son tres los requisitos para que proceda este recurso extraordinario: que se trate de acto firme, que el recurso se fundamente en la aparición de documentos de valor esencial que pueden ser incluso posteriores al momento de la resolución del asunto; y que los documentos evidencien el error de la resolución recurrida ${ }^{11}$.

Sobre si el recurso extraordinario de revisión procede aprovechando una sentencia posterior a un acto administrativo firme que invalida lo declarado por la Administración la sentencia 1315/2005 del TSJ de Cataluña de 19 de diciembre de 2005 ( $\mathrm{n}^{\circ}$ de recurso 45/2002) estima tal recurso extraordinario de revisión del artículo 118 de la LRJAP-PAG en un caso en que un acto administrativo excluyó a un empleado laboral en la participación de un concurso oposición por entender que aquel no era contratado laboral, quedando el acto firme y consentido. Pero, como con posterioridad una sentencia de lo laboral estimó que el interesado sí era personal laboral, éste presentó recurso de revisión del art. 118 LRJAP-PAC, que fue estimado por la sentencia 1315/2005 (sobre la base de la sentencia de lo social) ordenando a la Administración a admitir a tal recurrente en las pruebas, considerando el error jurídico de la Administración en la calificación de la relación de tal recurrente y considerando que tal sentencia de lo social era un documento posterior el artículo 118.1.2 de la LRJAPPAC, ya que en el momento de celebrarse las pruebas sí tenía esa condición de personal laboral que le fue negada por la Administración.

En esta línea, la STS de 29 de junio de 2010 (RJ 5954) considera que "una sentencia" que da la razón al interesado (evidenciando el error de un acto administrativo anterior a dicha sentencia de la Administración denegando la nacionalidad) es un "documento" que pone de manifiesto un "error de hecho" de la Administración y no un error jurídico como defendían la sentencia recurrida de la AN, el Consejo de Estado y el abogado del Estado ${ }^{12}$.

cho "tribunal" resolvió sin tener en cuenta un documento que era esencial en tanto que "de haberse conocido por el Tribunal Administrativo de Contratación Pública su presentación en plazo, no habría dictado la resolución $\mathrm{n}^{\circ} 46$ de 3 de mayo de 2012 por el que se tenía por desistida a la Asociación por entender que no había subsanado los defectos de capacidad apreciados".

11 Así también, el Dictamen 997/2013 de 28 de noviembre de 2013 dictamina a favor de la estimación del recurso extraordinario de revisión considerando que con posterioridad a la denegación de una beca apareció un documento que evidenciaba el error de la Administración, ya que dicho recurrente contaba con los requisitos para su concesión. En cambio, en el supuesto del dictamen 992/2001 de 26 de abril de 2001, el Consejo de Estado considera que el interesado no pone de manifiesto un error sino que plantea una "discrepancia con la valoración que hace la Administración".

12 Sin embargo, la STSJ de Castilla y León 376/2014 (PO 1525/2010) de 21 de febrero de 2014 sostiene que "en definitiva, no puede acogerse la pretensión de que la eficacia de una sentencia firme, anulatoria de concretos y determinados actos de la administración, se extienda a otro acto de la 
Distinto es el caso en que la Administración hubiera resuelto (a juicio del recurrente) sin atenderse a sentencias que solo aluden indirectamente al caso del acto recurrido por esta vía extraordinaria de revisión; en tal caso se trata de un error jurídico, no de hecho; evidenciándose que al interesado se le pasó el plazo para recurrir en el momento de dictarse el acto (STS de 28 de mayo de 2001, RJ 5768; no obstante, esta sentencia afirma también que "esgrimir como documento nuevo una sentencia firme que puso fin a otro proceso, a fin de justificar la interposición de un recurso extraordinario de revisión del artículo 118.1.2 de la LRJAP-PAC supone desnaturalizar el presupuesto legitimador de dicho recurso ya que éste no tiene como finalidad extender la eficacia de la cosa juzgada más allá de lo que dispone el artículo 86 de la Ley jurisdiccional de 1956, 72 de la vigente de 1998”).

La diferencia entre error de hecho y de derecho se precisa en muchas sentencias (STS de 26 de octubre de 2005 RJ 7826). Así, la STS de 26 de octubre de 2005 (RJ 7826, FJ $6^{\circ}$ ) afirma que el error de hecho se refiere a hechos inexistentes o cuando no se pondera otros que son reales y relevantes para lo que debía resolverse, resultando la inexactitud u omisión de las propias actuaciones obrantes en el expediente administrativo donde fue dictada la resolución. El error de derecho, en cambio, se produce cuando no hay controversia sobre los hechos materiales y la polémica se refiere a la calificación formal de los hechos en un plano normativo, o a sus consecuencias jurídicas. Es decir, el error de hecho se refiere a los presupuestos fácticos determinantes de la decisión administrativa, que no concurre si estamos ante una cuestión de interpretación jurídica (STS de 26 de abril de 2004, RJ 2822 FJ 4º).

En todo caso, por la vía de este recurso extraordinario de revisión se impide examinar cuestiones que debieron invocarse en la vía de los recursos ordinarios o en el jurisdiccional que puso fin a la vía administrativa, sin que tampoco pueda considerarse documento aparecido con posterioridad el que se confecciona con posterioridad (STS de 26 de abril de $2004 \mathrm{RJ} 2822$ y de 16 de febrero de $2005 \mathrm{RJ} 1844$, citadas en el dictamen del Consejo Consultivo de Castilla-La Mancha 194/2013 de 13 de junio de 2013) ${ }^{13}$.

propia Administración en virtud de la consideración de dicha sentencia firme como un documento nuevo demostrativo del error en que incurrió la Administración al resolver, pues, como hemos dicho, tal sentencia podrá contener una solución diferente de la adoptada por la Administración, pero no puede considerarse como un documento nuevo que evidencie el error de hecho en que incurrió la resolución administrativa, impugnada ante la propia Administración por el cauce del recurso extraordinario de revisión, lo que conduce a la desestimación del recurso" (conteniendo además esta sentencia una relación de fallos del Supremo sobre el concepto de error de hecho en esta línea restrictiva).

${ }^{13}$ De modo que no procede el recurso extraordinario de revisión cuando no se produce una "aparición de documento" ya que se trata de un "documento que se pudo obtener" y que en todo caso no informa sobre nada distinto de lo que ya obraba en el expediente administrativo (STS de 
En conclusión, a mi juicio, una sentencia ha de ser un "documento" susceptible de incluirse en la causa $2^{\text {a }}$ del artículo 118.1 de la LRJAP-PAC, siempre y cuando la controversia se refiera a un error de hecho.

Esta doctrina que consideramos equilibrada parece encontrar reflejo en la STS de 24 de junio de 2008 RJ 3275 FJ 3: "sí es posible que sentencias judiciales que hagan aflorar la realidad de tales situaciones lleguen a ser incluidas entre los documentos a que se refiere la causa $2^{a}$. Pero lo que no cabe incluir son sentencias que meramente interpretan el ordenamiento jurídico aplicado por esa resolución de modo distinto a como ella lo hizo".

Forzada en cambio podrá resultar la defensa cuando el interesado no se dirija meramente contra un acto administrativo firme, sino contra un acto cuya legalidad se ha refrendado por una sentencia de la jurisdicción contencioso-administrativa pese a que, fácticamente, quede contradicha por lo resuelto por una sentencia posterior, por ejemplo de la jurisdicción civil o social.

\section{La revisión de sentencias del artículo 102 de la LJCA 29/1998}

Precisan los tribunales que el denominado procedimiento de revisión más que un auténtico recurso, que no lo es, es en verdad una demanda rescisoria. No es un recurso, pues se presenta frente a sentencias firmes y la firmeza de una resolución judicial significa que contra ella no cabe recurso alguno (STS de 3 de noviembre de 1997). De ahí que haya abandonado la LJCA, mediante la reforma de noviembre de 2009, la terminología de recurso de revisión referido a la revisión de sentencias y haya adoptado la de procedimiento de revisión de sentencias.

La singularidad más notable de este procedimiento de revisión puede ser su procedencia contra sentencias firmes en presencia de una serie de motivos regulados en la LJCA (artículo 102 de la LJCA). Lo que se pretende, mediante la regulación de es-

26 de octubre de 2005, RJ 7826). Es decir, la clave viene a estar, en sentido desestimatorio al recurso extraordinario de revisión, en si el documento en cuestión no es tanto "posterior" como un documento "confeccionado" a fin de forzar la interposición de este recurso (STS de 26 de abril de

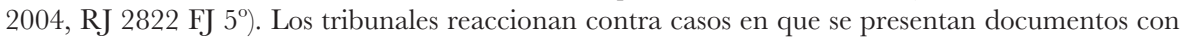
la finalidad de reabrir el debate ya resuelto sobre la base de documentos similares (STS de 21 de octubre de 2009, RJ 1118, FJ 4). O cuando destaca la ausencia de espontaneidad en su aparición (STS de 9 de octubre de 2007 RJ 7220). O también conviene tener en cuenta que se dictaminará desfavorablemente si el recurrente no explica las "causas que hubieran impedido la presentación de la documentación cuando se produjo aquel requerimiento" (Dictamen 991/(2001). En el Dictamen 55/13 de 20 de febrero de 2013 se ejemplifican este tipo de situaciones o aplicaciones del recurso extraordinario de revisión. 
tos motivos, es (según la STS de 30 de octubre de 1997, FJ 2) que la presente vía jurisdiccional no se convierta en una segunda o tercera instancia. Los Tribunales siguen un criterio de especial rigor formal en materia de revisión. Su justificación se busca en el hecho de que este procedimiento pretende la revisión de una sentencia firme, por su naturaleza irrecurrible; de ahí que sea habitual que no concurran sus presupuestos legales en el caso concreto (STS de 18 de mayo de 2002). La trascendencia del procedimiento de revisión, en la medida en que mediante él se puede destruir la presunción de veracidad y de justicia propia de la santidad de la cosa juzgada, obliga a una «extrema rigurosidad en las causas que permiten su interposición», dice una STS de 3 de noviembre de 1997.

Los dos primeros motivos previstos en el artículo 102.1 de la LJCA hacen referencia a la existencia de documentos relacionados con el proceso que se sustanció en su día y que se pretende sea revisado. Habrá lugar a la revisión, concretamente, si después de pronunciada la sentencia se recobraran documentos decisivos, no aportados por causa de fuerza mayor o por obra de la parte en cuyo favor se hubiera dictado. O, también, si aquélla hubiera recaído en virtud de documentos que, al tiempo de dictarse la sentencia, ignoraba una de las partes haber sido reconocidos y declarados falsos o cuya falsedad se reconociese o declarase después. La jurisprudencia ha precisado el término «documentos», común a ambos motivos, afirmando que no son tales las sentencias, ni los autos, ni las providencias (STS de 29 de octubre de 1997). Asimismo, un cambio de criterio en la jurisprudencia se ha entendido como un motivo insuficiente para plantear con éxito recurso de revisión (ATS de 30 de octubre de 2006 recurso 175/2003). Por su parte la STS de 6 de febrero de 2006 (RJ 2835) precisa que la LJCA se refiere a los documentos mismos, es decir, al soporte material que los constituye y no, de entrada, a los datos en ellos constatados.

Además, los documentos han de ser recobrados con posterioridad al momento en que haya precluido la posibilidad de aportarlos al proceso, de modo que no es un " $d 0^{-}$ cumento recobrado" aquel que ya obra en autos y pudo ser tenido en cuenta por la Sala al dictar su sentencia, sin que exista retención de documento cuando aquel ha obrado en el proceso y pudo ser valorado por el Tribunal de instancia (STS de 6 de febrero de 2006, RJ 2835). En este contexto la STS de 12 de junio de 2009 (RJ 6580) precisa que el documento ha de existir antes de la sentencia; han de ser decisivos en el sentido de que podrían haber variado su contenido; ha de haber sido imposible su aportación en el momento procesal oportuno por fuerza mayor que no se presume sino que ha de acreditarse. De modo que, en el caso juzgado por tal STS de 12 de junio de 2009 no procede el recurso de revisión ya que los documentos que se aportan por el recurrente no consta que hubiesen sido retenidos por dolo de la contraparte (...) ya que la falta de presentación del documento fue debido a la falta de diligencia del actor intentando ahora interponer este recurso para reabrir la prueba que en su día no se practicó. Además, si los documentos que se consideran recobrados se encontraban 
todos antes de la fecha de la sentencia e incluso antes del recurso contencioso-administrativo en oficinas públicas, no cabe apreciar retención de documentos ni fuerza mayor ni obra de la otra parte que impidiesen a la recurrente en revisión su conocimiento y aportación al juicio.

Los documentos han de ser anteriores a la sentencia (STS de 11 de diciembre de 1997, FJ 3; STS de 16 de enero de 2014 recurso 3/2013). Este presupuesto básico requiere además que el documento no se haya podido obtener antes de que recayera sentencia firme, si se hubiera solicitado (STS de 1 de diciembre de 1997).

Y por otra parte han de ser documentos decisivos, no intrascendentes, de suerte que tengan eficacia bastante para decidir la contienda diversamente a como lo hizo la Sala $a$ quo (STS de 30 de octubre de 1997 FJ 2). Por tanto, la STS de 29 de marzo de 2012 recurso $37 / 2010$, citando otras (FJ $2^{\circ}$ ) afirma que no procede este recurso de revisión invocando éste una sentencia posterior a la que se pretende revisar, ya que no es un documento decisivo al dictarse aquella, al no existir por entonces. En esta línea, STS de 20 de octubre de 2011 (recurso 17/2010), STS de 23 de febrero de 2012 recurso 19/2009, STS de 14 de febrero de 1998 recurso 354/1995, STS de 28 de noviembre de 2012 (recurso 43/2011).

Dejamos al margen un examen de los demás motivos. Es suficiente lo expuesto para darse cuenta de que los particulares han de encajar o entender que la suerte es un factor importante que habrá podido influir en la resolución de su asunto, debiendo comprender que otro justiciable haya podido obtener un resultado diferente. No obstante, es claro que dependiendo del caso concreto podrán abrirse posibles opciones de defensa.

E. Pese a la cosa juzgada, la extensión de los efectos de la sentencia y el rico ámbito de aplicación de los incidentes de ejecución. Contando con un plazo de 15 años para instar la ejecución de una sentencia

El tema de la cosa juzgada presenta ciertas singularidades en el proceso administrativo, ya que se plantea la posibilidad de extender ultra partes los efectos de una sentencia, por tanto en favor de terceros que no fueron parte en el proceso pero que se encuentren en idéntica situación que el sujeto que obtiene judicialmente una determinada prestación administrativa. Por otra parte, es preciso tener en cuenta que la sentencia anulatoria producirá efectos para todas las personas afectadas y, por tanto, no sólo en favor de quienes hayan sido parte en el proceso. No vamos más que a presentar esta densa y rica temática. Es preciso tener en cuenta que, a diferencia de los procesos civiles por ejemplo, en los contencioso-administrativos es muy característica la presentación de incidentes de ejecución por los que se puede intentar la exten- 
sión del fallo en favor de quien lo promueve, con resultados a veces casuísticos. Sin perjuicio de la posibilidad de orientar la ejecución del fallo en un sentido u otro, considerando que no existen siempre reglas claras de aquello que significa la anulación de un acto administrativo (¿retroacción, posibles subsanación, imposibilidad, indemnización, repetición del procedimiento?) sin que la diferencia entre nulidad y anulabilidad resuelva todas las posibles incidencias.

Conviene también advertir que, frente a lo que pudiera pensarse, el artículo 110 de la LJCA es un precepto desbordado por una realidad práctica que permite intentar el planteamiento de la extensión de los efectos de la sentencia más allá de los casos que cita el legislador, con resultados igualmente diversos en la praxis judicial; subjetividad judicial siempre criticable, pero que en este caso quizás sea la menos mala de las soluciones posibles, es decir, preferible en todo caso frente a un posible criterio del legislador que lleve a mermar la tutela judicial efectiva de posibles interesados.

Los órganos jurisdiccionales, por tanto, pueden acceder a tramitar los incidentes de ejecución como forma de otorgar tutela judicial efectiva (STS de 27 de septiembre de 2011 recurso de casación 6407/2009 ${ }^{14}$ ), permitiendo la legitimación a las personas afectadas para instar la ejecución forzosa de la sentencia (STS de 7 de junio de 2005, donde una asociación vecinal exigía el cumplimiento de la ejecución de una sentencia que anulaba la licencia otorgada para la construcción de tres bloques adosados situados en el entorno del monumento histórico-artístico de Pazo de Quiñones de León), si bien más recientemente la STS de 23 de abril de 2010 deniega la personación de la asociación ecologista en la fase de ejecución por no haber sido parte y no tener la consideración de parte afectada conforme al artículo 104.2 de la LJCA.

${ }^{14}$ Así, por ejemplo, en el caso de la ilustrativa STS de 27 de septiembre de 2011 el TS admite y estima tal incidente en un caso en que un colectivo de propietarios (terceros procesalmente) pretende obtener el mismo beneficio logrado por otro particular que, en un proceso, había conseguido una sentencia por la que se anulaba un Acuerdo de 17 de abril de 1997 por el que se aprobaba la revisión del PGOU de Madrid (STSJ de Madrid no 636 de 15 de junio de 2002 confirmada por la STS de 15 de febrero de 2006) y por la que se otorgaba el derecho al recurrente de beneficiarse del mismo régimen que dicho Plan había seguido con respecto a otros propietarios, a quienes el PGOU en cuestión había aumentado la edificabilidad. En este caso, la sentencia era anulatoria pero reconocía una situación jurídica individualizada a favor del recurrente victorioso. No obstante, en este ejemplo, el TS estima el recurso por entender que la sentencia es ejecutable, frente al Auto del TSJ de Madrid que estimó la causa de imposibilidad de ejecución. La Sala de instancia había permitido la extensión de los efectos de la sentencia pero no terminaba de otorgar a los terceros una posición procesal autónoma de igual rango que a la recurrente que obtuvo la sentencia de 15 de junio de 2002, pero finalmente la STS de 27 de septiembre de 2011 estimó el recurso contra el auto del TSJ de Madrid denegatorio del incidente de ejecución por causa de imposibilidad. 
Se admite la posibilidad, cuando la Administración está incumpliendo una sentencia, de presentar incidente de ejecución alegando incumplimiento de la sentencia por parte de dicha Administración, o bien plantear además, junto a lo anterior, un nuevo recurso contra el acto incumplidor de la sentencia en cuestión, tal como afirma expresamente la STS de 28 de septiembre de 2012 (rec. de casación 1009/2011), si bien la admisión del primero podrá provocar la inadmisión del segundo cuando la parte demandada oponga litispendencia por este hecho (sentencia del Juzgado de lo contencioso-administrativo $\mathrm{n}^{\circ} 22$ de Madrid de 1 de septiembre de 2010, PO 120/2009; sentencia del Juzgado contencioso-administrativo $\mathrm{n}^{\circ} 31$ de Madrid 365/2010, de 20 de septiembre de 2010, PO 108/2009, ambas por haber litispendencia con la tramitación de un incidente en el TS).

\section{Litigar pese a la cosa juzgada, tras la inadmisión del re- curso}

Es claro que, en torno a todos estos temas, nadie podrá esquivar la incertidumbre que surge cuando abandona los planteamientos pacíficamente asentados en la norma procesal. En este sentido, ha de entenderse también que, junto a las sentencias que citemos seguidamente, puede haber otras con otros criterios diferentes.

Según apunta la STS de 29 de septiembre de 1980 la inadmisión constituye «un verdadero requisito o presupuesto procesal de procedibilidad, de tal forma que la acción carece de viabilidad. Y esta exigencia nada tiene que ver con la naturaleza del acto que se trata de anular, ni con el instituto de la prescripción, y sí con el carácter de la resolución a efectos de ganar o no firmeza. Por lo tanto, y ante la extemporaneidad del recurso de reposición, hemos de estimar infringido el citado art. 52 de la Ley que acarrea la inadmisibilidad postulada, conforme reiterada jurisprudencia sentencias del TS de 27 mayo 1964, 21 octubre 1965, etc.-».

Sin embargo, para la STSJ de la Comunidad Valenciana (Sala de lo contencioso-administrativo) de 8 de junio de 1998, recurso 4042/1995, «una sentencia de inadmisibilidad no produce efectos de cosa juzgada, pues no ha entrado a valorar y a pronunciarse sobre el fondo litigioso, dejando imprejuzgado el acto o disposición administrativa sujeta a revisión. La inadmisibilidad supone la ausencia de los requisitos procesales exigibles, lo que obliga a rechazar formalmente el recurso sin siquiera examinar las pretensiones de fondo de las partes. Tal como reiterada jurisprudencia del Tribunal Supremo ha venido indicando (SS. 11 diciembre 1969, 19 enero 1970, 19 mayo 1976, 27 enero 1977, 12 mayo 1977, 10 noviembre 1977, 20 octubre 1982 y 7 octubre 1986, entre otras muchas) la sentencia de inadmisibilidad carece de efectos propios de la cosa juzgada, no produce efectos ejecutivos ni tiene repercusión en las relaciones jurídico-materiales, pues se limita a rechazar un recurso por incumplimiento de determinados requisitos de indole procesal. En tal sentido, dicha sentencia no es título de ejecución por no haber pronunciamiento 
sobre el acto o disposición impugnada, de forma que éstos permanecen imprejuzgados». «La inadmisibilidad del recurso contencioso-administrativo, al no contener pronunciamiento sobre el fondo del asunto, no produce efecto alguno, ni jurídicos procesales ni declarativos (no tiene los efectos propios de la cosa juzgada, según la jurisprudencia antes citada) ni ejecutivos, ni jurídico materiales. El acto o disposición objeto de impugnación subsistirán y producirán plenos efectos sin que la sentencia añada nada nuevo a la realidad jurídico-material existente antes del proceso» ${ }^{15}$.

Las sentencias en las que se recoge una causa de inadmisibilidad "carecen del valor de cosa juzgada material como ha declarado el TS en multitud de sentencias, de las que pueden servir de ejemplo las de 19 de enero de 1970 y 12 de mayo de 1977 " (STS de 7 de octubre de 1986 ponente S. Gutiérrez de Juana, aceptando los considerandos de la sentencia apelada de la Audiencia Territorial de Valladolid de 3 de julio de 1984, y rechazando la causa de inadmisibilidad del abogado del Estado invocando cosa juzgada).

También puede citarse la sentencia del Tribunal Superior de Justicia de las Islas Canarias (Las Palmas de Gran Canaria) 24 de febrero de 2005 (JUR 109152): "TERCERO. Como es obvio la existencia de un proceso contencioso-administrativo seguido ante esta Sala con el número 726/92 dejó sin prejuzgar la cuestión de fondo toda vez que fue inadmitido por extemporáneo, esto es, no produjo otros efectos que los derivados de la inadmisibilidad y por tanto no constituyó obstáculo alguno a otro proceso sobre el mismo objeto al tratarse de una sentencia que carece de valor de cosa juzgada material (Sentencia del Tribunal Supremo de 12 de mayo de 1977) al no haber producido efecto alguno en las relaciones jurídicas materiales".

Por otra parte, obviamente, si el acto recurrido es diferente no se puede oponer cosa juzgada, ya que el segundo acto es diferente pese a que el segundo pronunciamiento "ha de atenerse al contenido de la primera sentencia en el caso de que formen parte de su tema decidendi cuestiones ya decididas en la sentencia firme anterior sin contradecir lo dispuesto en ella, sino tomándola como punto de partida" (vinculación positiva o prejudicial de la cosa juzgada, por haber coincidencia parcial), mientras que la negativa o excluyente es la que obliga al órgano judicial a declarar inadmisible el proceso cuando advierte que el objeto de éste coincide o es jurídicamente idéntico a lo resuelto en sentencia firme en un proceso anterior (STS de 2 de diciembre de 2013 recurso 397/2010). Ahora bien, el segundo si es confirmación de otro precedente habría inadmisión. 3000.

${ }^{15}$ J. GONZÁLEZ-PÉREZ, Código de la justicia administrativa, vol. 2, segunda edición, 2008, p. 
Con todos estos elementos, sin perjuicio de otros posibles, es preciso contar en el caso concreto.

\section{Litigar pese a haber desistido. Cosa juzgada y desisti- miento}

Tras un desistimiento, que no renuncia, ha de ser de recibo poder volver a instar la acción procesal siempre que hubiera plazo para ello, tal como establece la sentencia del TS de 21 de febrero de 2006 (RJ 2006/1933): "En todo caso, y al margen de la indemostrada identidad de actos debemos dejar constancia de que lo decidido por la Sala fue exclusivamente el desistimiento de aquel procedimiento, mas no la renuncia a ningún tipo de acción en relación con el Convenio Urbanístico. En relación con tal circunstancia ya dijimos en nuestra STS de 30 de octubre de 1990 (RJ 1990, 10062) que: «El desistimiento, que para ser eficaz debe hacerse pura y simplemente, no consume la acción, ya que a diferencia de la renuncia a ésta, el único efecto que produce es dar por terminado el proceso. Lo que ocurre es que en este orden jurisdiccional en que el ejercicio de la acción está sujeto a plazos de caducidad, generalmente breves, el desistimiento suele llevar aparejado la extinción de la acción y consiguientemente la firmeza, por consentimiento, del acto o disposición recurridos, pero no como un efecto propio y directo de este modo anormal de terminación del proceso, sino porque producido el desistimiento es frecuente que se encuentre agotado el plazo legalmente previsto para ejercitar de nuevo la acción. Sin embargo en este caso, concurren circunstancias, singulares, como a continuación se verá, que revelan además una voluntad constante del actor dirigida a impugnar las dos resoluciones a que se ha hecho relación (...). Y, con anterioridad, STS de 28 de octubre de 1988 (RJ 1988, 8300). ${ }^{16}$

En fin, el presente tema tiene luces y sombras, que es lo que ocurre cuando se debaten cuestiones más allá de las vías más ordinarias de defensa. Si uno se separa de tales planteamientos procesales, ha de asumir la existencia de riesgos e incertidumbres y de mayor, si cabe, subjetividad judicial. La firmeza del acto administrativo es uno de los mayores problemas desde el punto de vista de las garantías del administrado, lo que obliga a estar muy atentos intentando abrir espacios legítimos por donde

${ }^{16}$ Interesante en la materia es la STSJ 434/2008, de Cataluña de 30 de mayo de 2008 (n ${ }^{\circ}$ de recurso 320/2006), a cuya lectura nos remitimos (FJ quinto, admitiendo una nueva acción tras una petición y posterior desistimiento una vez se tienen todos los datos para litigar). Y STSJ de la Comunidad Valenciana de 12 de noviembre de 2013 (n ${ }^{\circ}$ recurso 683/2011 y n ${ }^{\circ}$ sentencia 833/2013 FJ segundo), STS de 13 de diciembre de 2006 8116/2006, no de recurso 3138/2005 FJ $2^{17}$ y STS de 16 de febrero de 2009 455/2009, $\mathrm{n}^{\circ}$ de recurso 1887/2007. 
poder defenderse. A veces las situaciones son especialmente complejas porque colisiona la idea de la debida tutela de los sujetos (afectados por la firmeza) con la seguridad jurídica. Es preciso aportar claridad al respecto y criterios y fundamentos en relación con las distintas posibles situaciones. 